\title{
Beta-Hydroxybutyrate Measurement
}

National Cancer Institute

\section{Source}

National Cancer Institute. Beta-Hydroxybutyrate Measurement. NCI Thesaurus. Code C96568.

The determination of the amount of beta-hydroxybutyrate present in a sample. 